\title{
Congenital oesophageal stenosis due to tracheobronchial remnants
}

\author{
A. K. D E I R A N IY A ${ }^{1}$ \\ Cardiothoracic Unit, Harefield Hospital, Harefield, Middlesex \\ and The Children's Hospital, Birmingham
}

\begin{abstract}
Deiraniya, A. K. (1974). Thorax, 29, 720-725. Congenital oesophageal stenosis due to tracheobronchial remnants. Two cases of distal oesophageal obstruction due to tracheobronchial remnant after the successful treatment of proximal oesophageal atresia with an associated tracheo-oesophageal fistula are reported. This association of congenital distal oesophageal stenosis due to tracheobronchial remnant with oesophageal atresia and tracheo-oesophageal fistula has not previously been reported in the literature. The diagnosis should be suspected in cases of distal oesophageal obstruction presenting in childhood or adult life with a history dating back to infancy or childhood. Radiologically a short stenotic non-relaxing segment is the hallmark. There is no hiatus hernia and no gastro-oesophageal reflux. Surgical excision is recommended and can be achieved easily through a thoracic approach. Dilatation is difficult, at times impossible and occasionally hazardous, and any benefit is transient. Excision of the stenotic segment with primary end-to-end anastomosis is the method of choice and almost always possible.
\end{abstract}

Congenital stenosis of the lower oesophagus is an uncommon lesion. Beatty (1928) found two such cases in over 13,000 postmortem examinations. Even rarer are oesophageal strictures due to intramural tracheobronchial remnants . Twelve such cases have been reported in the English and German literature (Frey and Duschl, 1936; Castleman, 1956; Bergmann and Charnas, 1958; Spath and Ratzenhofer, 1959; Kumar, 1962; Paulino, Roselli, and Aprigliano, 1963; Ishida, Tsuchida, Saito, and Tsunoda, 1969; Fonkalsrud, 1972; Goldman and Ban, 1972).

The present communication reports the occurrence of distal oesophageal obstruction in two infants as a result of ectopic tracheobronchial tissue following the initial successful surgical treatment of proximal oesophageal atresia with associated tracheo-oesophageal fistula.

A survey of the literature has not revealed a similar case.

\section{CASE REPORTS}

CASE 1. A full-term normal female infant was delivered on 26 April 1970 after an uneventful pregnancy. Shortly after birth oesophageal atresia was

1Present address: Cardiothoracic Unit, Queen Elizabeth Hospital, Birmingham B15 2TH suspected because of choking spells and constant dribbling of frothy sputum. Clinical examination was unremarkable. A soft rubber catheter was held up at $10 \mathrm{~cm}$ from the nostrils. Radiological examination confirmed the presence of oesophageal atresia with an associated tracheo-oesophageal fistula.

Right thoracotomy was performed in the prone position through the bed of the fourth rib. A large pouch overlying the tracheo-oesophageal fistula was found. The lower oesophageal segment was mobilized and the fistula was divided. The resultant opening in the trachea was closed. The upper pouch was opened and anastomosed to the lower oesophageal segment with $5 / 0$ sutures.

The postoperative course was satisfactory and she was discharged home on the 14th day. She was followed up in the paediatric department and was making good progress apart from repeated chest infections.

In October 1970 she was readmitted to hospital because of recurrent attacks of increasing difficulty in feeding, dyspnoea, and vomiting. Oesophagoscopy showed no abnormality; no stricture was seen.

In December 1970 she was re-admitted with dysphagia, cyanosis, and dyspnoea. On examination she was wasted and dehydrated. There was intercostal recession and stridor. A diagnosis of aspiration pneumonia, secondary to oesophageal stenosis, was made. She was treated with antibiotics, intravenous infusions, humidity, and oxygen therapy. She made a rapid 
recovery. Stools had previously been noted to be frequent, offensive, and bulky. She had refused milk feeds persistently but would take clear fiuids avidly. Coeliac disease was suspected. A barium swallow and meal confirmed the presence of an oesophageal stricture at the lower end of the oesophagus just above the diaphragm and demonstrated a malabsorption pattern consistent with coeliac disease (Fig. 1). Oesophagoscopy at this stage revealed a stricture with inflamed edges which was dilated. Fat studies confirmed the presence of steatorrhea. Jejunal biopsy using a special

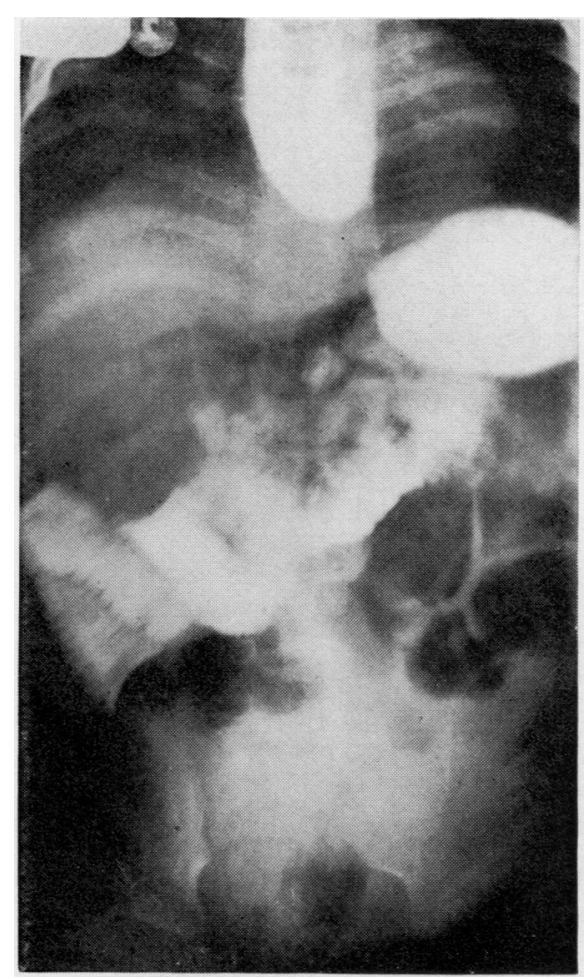

FIG. 1. Barium studies showing oesophageal dilatation proximal to an area of oesophageal stenosis situated at the level of the diaphragm.

capsule was attempted but failed due to hold-up of the capsule at the lower end of the oesophagus. A gluten-free diet was then started but it soon became apparent that her oesophageal stricture severely interfered with her intake of such diet. On 23 January 1971 a Witzel gastrostomy and open jejunal biopsy was performed. Gastrostomy feeding with a glutenfree diet resulted in a remarkable weight gain. Jejunal biopsy showed severe villous atrophy with inflammatory cells. Dysphagia persisted and it was decided to defer treatment of the oesophageal stricture to allow for further weight gain and growth. Following her discharge from hospital she was re-admitted to another hospital with complete oesophageal obstruction due to a foreign body impacted at the stricture. This was removed and proved to be a match-stick.

In July 1971 she was admitted to Harefield Hospital for definitive treatment. Preoperative oesophagoscopy revealed a tight oesophageal stricture which could not be dilated. The gastrostomy stoma was excised through a thoracoabdominal approach, and the resultant defect in the stomach was repaired. The oesophagus was mobilized. A short resilient stricture situated $3 \mathrm{~cm}$ above the cardia-oesophageal junction was found. There was considerable oesophageal dilatation above. An oesophageal segment measuring $5 \mathrm{~cm}$ and containing the stricture was excised, and a short colonic loop based on the left colic artery was anastomosed to the lower end of the oesophagus and the fundus of the stomach. A pyloroplasty was performed. Her postoperative course was uneventful.

Histological examination of the resected stenotic area showed a crescent of mature cartilage extending over one-third of the circumference, lying internal to the oesophageal muscle layer. The overlying muscle layer was attenuated (Fig. 2). Respiratory seromucous glands were abundant (Fig. 3). The stenotic segment was lined by squamous-cell epithelium. A postoperative barium swallow showed no hold-up and satisfactory passage of the contrast into the stomach.

CASE 2. A full-term male infant was delivered on 18 June 1973 after an uneventful pregnancy. Immediately after birth an imperforate anus was noted on clinical examination. Shortly afterwards oesophageal atresia was suspected because of continuous drooling of saliva and choking spells. The passage of a nasal catheter was held up at $11 \mathrm{~cm}$ from the nostril. Radiological studies confirmed the diagnosis of oesophageal atresia with an associated tracheo-oesophageal fistula and rectal agenesis.

Six hours after birth a right thoracotomy through the bed of the fourth rib was performed. The fistula was divided and the resultant opening in the trachea was closed. A primary end-to-end anastomosis of the upper oesophageal pouch and the lower oesophageal segment was performed. At the age of 36 hours a high sigmoid colostomy was performed because of increasing abdominal distension. His postoperative course was satisfactory but he was noted to take his feeds very slowly. A barium swallow was performed on 3 July 1973 and revealed a moderate localized stricture at the anastomotic site and a further tighter stricture $2 \mathrm{~cm}$ above the diaphragm with a small expanded area below it. No reflux could be elicited (Fig. 4). He was discharged home 21 days after admission.

When seen in the paediatric surgical follow-up department on 6 August 1973 he was well. He was seen again on 10 January 1974 shortly after he developed a chest infection. He was noted at that time to have widespread bilateral coarse rales. When seen on 8 April 1974 his mother reported that he had been regurgitating semisolids but had had no difficulty 


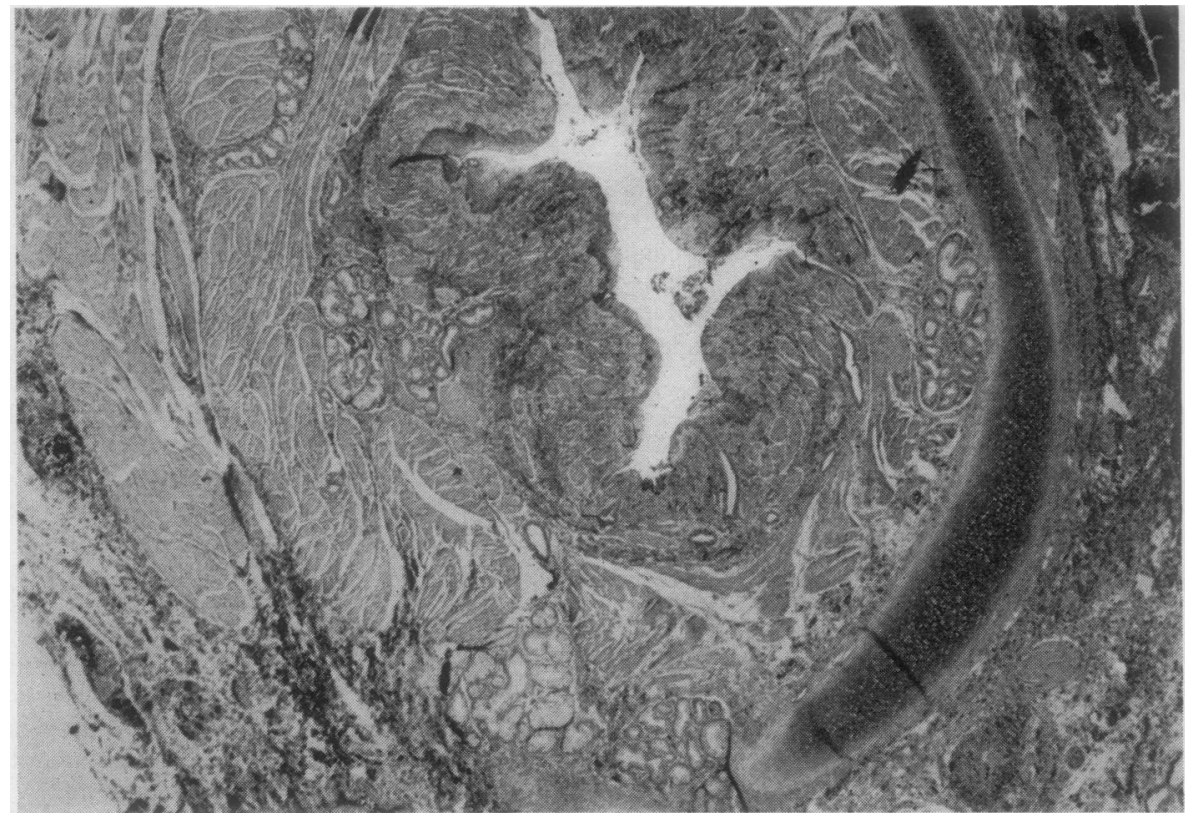

FIG. 2. Low-power photomicrograph showing the topographical organization of the stenotic segment. Note the crescent of cartilage and the abundant bronchial seromucous glands (Haematoxylin and eosin $\times 12$ ).

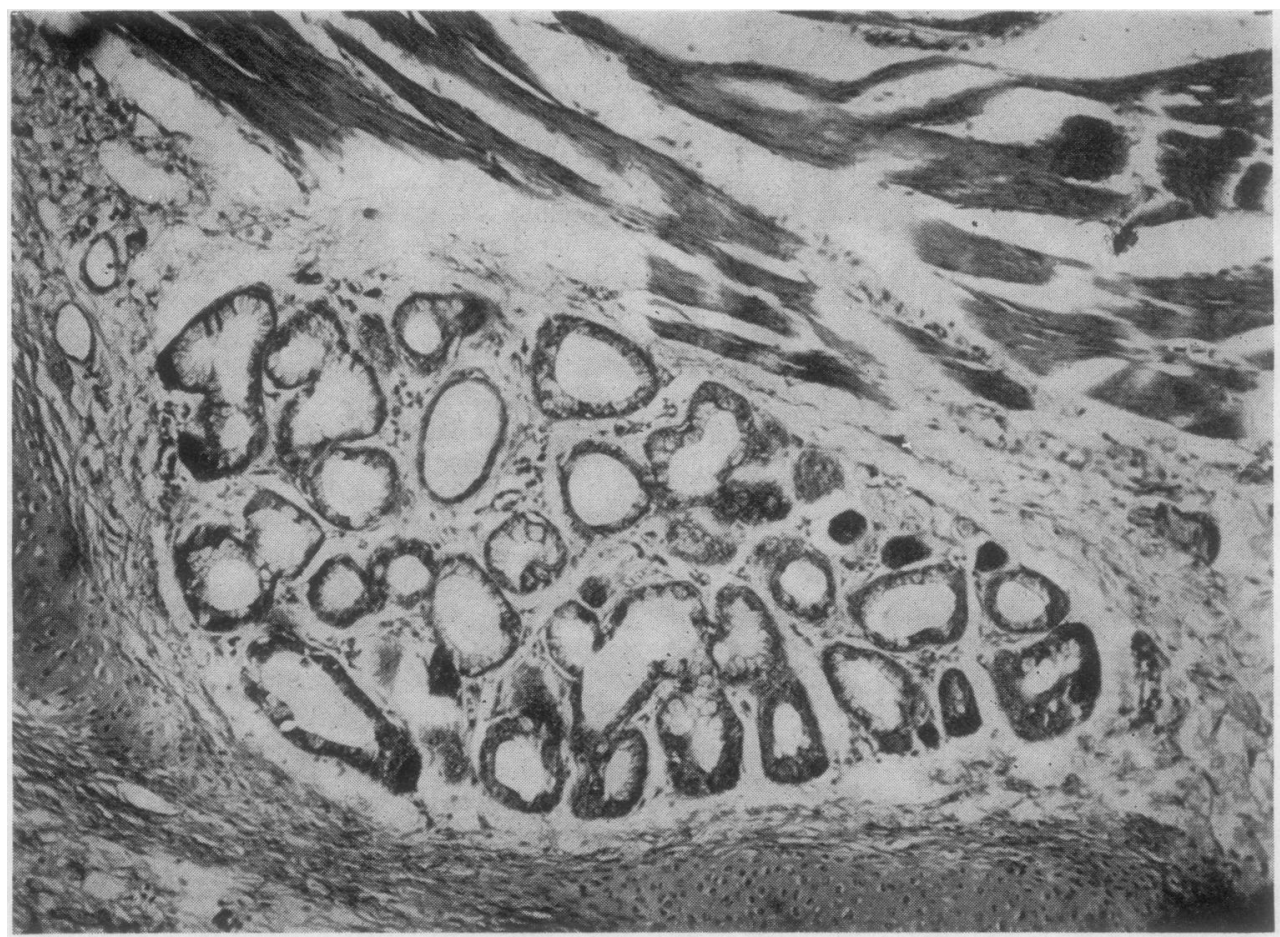

FIG. 3. High-power view of a group of 'bronchial' seromucous glands showing the numerous secretory cells $(H$ and $E \times 120)$. 


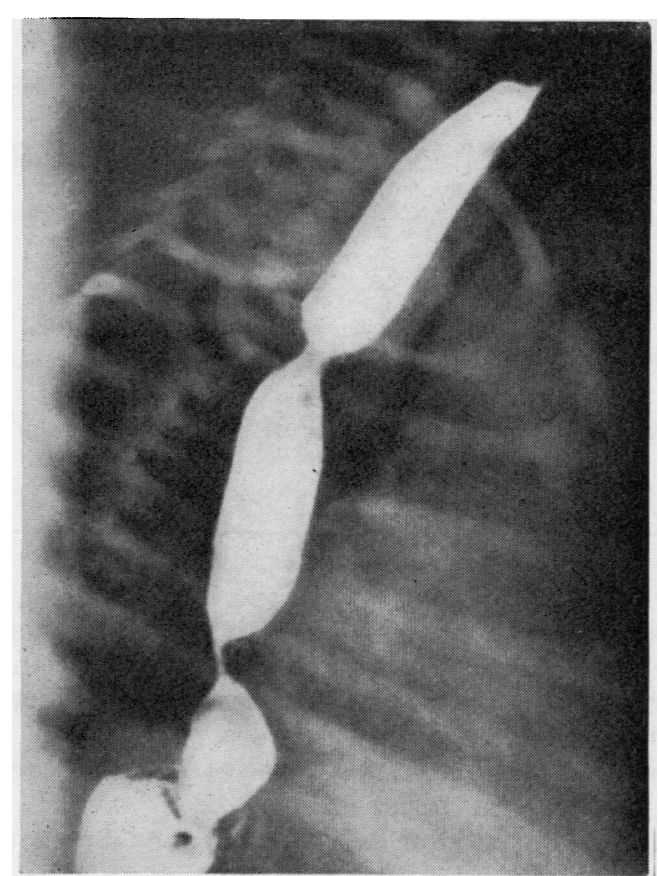

FIG. 4. Barium studies performed at age 10 days showing two areas of oesophageal narrowing, the upper one at the site of the anastomosis which, although evident on this study, was not present at oesophagoscopy performed nine months later. The lower stenotic segment situated just above the diaphragm represents the site of tracheobronchial remnant.

with fluids over the past three months and had suffered repeated chest infections despite medication with antibiotics. Once again diffuse coarse rales were heard over both lung fields, and a chest film showed bilateral perihilar inflammatory changes. A diagnosis of distal oesophageal stenosis, probably due to reflux oesophagitis, and associated aspiration pneumonitis was made.

Oesophagoscopy was performed at 2.45 p.m. on 1 May 1974. The oesophagus was found to be grossly dilated. The site of the anastomosis was satisfactory with no evidence of stenosis. The oesophagoscope was passed easily to $19 \mathrm{~cm}$ when a tight stricture was encountered. There was no evidence of oesophagitis. The stricture was dilated with apparent ease. He was discharged home at $7.00 \mathrm{pm}$. He was fed at $8.30 \mathrm{pm}$ but took very little and cried incessantly. He was put in his cot at $9.30 \mathrm{pm}$ and found dead the following morning.

At necropsy there was a perforation at the site of the stricture measuring $0.6 \mathrm{~cm}$ in diameter. The stricture was located at the oesophagogastric junction and there was leakage of oesophageal contents into the mediastinum and the left pleural cavity. The cardia was elevated and partially pulled through the diaphragm, forming a small hiatus hernia. The lower sigmoid colon ended abruptly at the level of the bladder neck immediately posterior to the prostate gland. Histological examination of the stenotic area revealed a picture identical with that of case 1 with abundant tracheobronchial seromucous glands and a crescent of cartilage occupying one-third of the circumference of the stenotic segment. The stenotic segment was lined by normal transitional epithelium.

\section{DISCUSSION}

Frey and Duschl (1936) reported the first case of oesophageal stenosis due to heterotopic tracheobronchial tissue in a 19-year-old girl who died with a diagnosis of achalasia. Histological examination showed the presence of cartilage in the cardia. Castleman (1956) reported a similar case in a 52-year-old man with dysphagia dating back to early childhood. Since then Kumar (1962), Paulino et al. (1963), and Ishida et al. (1969) have reported another six cases. Five cases appearing in the Japanese literature were alluded to by Ishida. The latter cases will not be discussed any further. In all these cases cartilage and other tracheobronchial tissues were present. Bergmann and Charnas (1958), Spath and Ratzenhofer (1959), and Fonkalsrud (1972) reported three cases of oesophageal obstruction due to tracheobronchial remnants other than cartilage. Goldman and Ban (1972) described an unusual case of oesophageal atresia and heterotopic tracheobronchial tissue in the proximal segment. This case will be referred to later (Table).

Despite the wide variation in age at the time of admission all cases had symptoms of oesophageal obstruction which dated back to infancy or childhood. Dysphagia coincided with the weaning stage in some cases and was first noted in our patients at this time. Recurrent respiratory infections, probably the result of aspiration pneumonitis, were noted in a number of cases and were a prominent feature in our cases. Barium swallow showed a stricture at the distal end of the oesophagus or in its lower third. Oesophageal dilatation proximal to the stricture was marked. There were nine females and four males.

A correct preoperative diagnosis of the underlying aetiology of the stenosis was not reached in any case. Achalasia was considered on several occasions; other preoperative diagnoses included webs, fibromuscular stenosis, and stricture secondary to gastric reflux. In both our cases the diagnosis was established only on histological examination of the stenotic segment. 
T A B L E

REPORTED CASES OF TRACHEOBRONCHIAL REMNANTS IN THE OESOPHAGUS

\begin{tabular}{|c|c|c|c|c|c|c|c|}
\hline \multirow[b]{2}{*}{ Author } & \multirow[b]{2}{*}{ Age } & \multirow[b]{2}{*}{ Sex } & \multirow[b]{2}{*}{ Age at Onset } & \multirow[b]{2}{*}{ Site of Stenosis } & \multicolumn{3}{|c|}{ Histological Components } \\
\hline & & & & & Cartilage & Glands & Resp. Epithelium \\
\hline $\begin{array}{l}\text { Frey and Duschul (1936) } \\
\text { Castleman (1956) } \\
\text { Bergmann and Charnas (1958) } \\
\text { Spath and Ratzenhofer (1959) } \\
\text { Kumar (1962) } \\
\text { Paulino et al. (1963) } \\
\text { Paulino et al. (1963) } \\
\text { Ishida et al. (1969) } \\
\text { Ishida et al. (1969) } \\
\text { Ishida et al. (1969) } \\
\text { Fonkalsrud (1972) } \\
\text { Goldman and Ban (1972) } \\
\text { Present study (1974) } \\
\text { Case 1 } \\
\text { Case } 2\end{array}$ & $\begin{array}{l}19 \\
51 \\
57 \\
49 \\
10 \\
8 \mathrm{mth} \\
14 \mathrm{mth} \\
17 \mathrm{mth} \\
4 \\
5 \\
1 \\
1 \mathrm{~d} \\
2 \\
10 \mathrm{mth}\end{array}$ & $\begin{array}{l}\mathbf{F} \\
\mathbf{M} \\
\mathbf{F} \\
\mathbf{F} \\
\mathbf{F} \\
\mathbf{F} \\
\mathbf{M} \\
\mathbf{M} \\
\mathbf{M} \\
\mathbf{F} \\
\mathbf{F} \\
\mathbf{F} \\
\mathbf{M}\end{array}$ & $\begin{array}{l}\text { ? } \\
3 \text { years } \\
\text { Childhood } \\
\text { Birth } \\
4 \text { months } \\
\text { Birth } \\
6 \text { months } \\
7 \text { months } \\
6 \text { months } \\
1 \text { year } \\
6 \text { months } \\
\text { Birth } \\
6 \text { months } \\
5 \text { months }\end{array}$ & $\begin{array}{l}\text { Distal end } \\
\text { Distal end } \\
\text { Lower third } \\
\text { Lower third } \\
\text { Distal end } \\
\text { Lower third } \\
\text { Distal end } \\
\text { Distal end } \\
\text { Distal end } \\
\text { Distal end } \\
\text { Lower third } \\
\text { Upper third } \\
\text { Lower third } \\
\text { Lower third }\end{array}$ & $\begin{array}{l}+ \\
\pm \\
\dot{+} \\
+ \\
+ \\
+ \\
+ \\
+ \\
+ \\
+ \\
+ \\
+\end{array}$ & $\begin{array}{l}+ \\
+ \\
+ \\
+ \\
+ \\
\dot{+} \\
\dot{+} \\
+ \\
+ \\
+ \\
+ \\
+ \\
+ \\
+ \\
+\end{array}$ & $\begin{array}{l}\overline{+} \\
+ \\
+ \\
\bar{t} \\
+ \\
+ \\
+ \\
+ \\
\overline{+} \\
- \\
- \\
-\end{array}$ \\
\hline
\end{tabular}

The diagnosis of this anomaly should be considered in cases of congenital oesophageal stenosis. Radiologically there is a short distally located stenotic segment, which fails to relax on swallowing or on nitrite inhalation. There is no evidence of gastric reflux. Oesophagoscopy showed a resilient stricture with no evidence of oesophagitis.

The treatment of this variety of congenital oesophageal stenosis by dilatation is unsatisfactory. Dilatation is often difficult, at times impossible. In our second case the oesophagus was perforated during dilatation. Any improvement following dilatation is short-lived. Definitive treatment involves excision of the stenotic segment and restoration of alimentary continuity by an end-to-end anastomosis. This is almost always possible. Both the thoracic and abdominal approaches have been employed. In our first case a short colon loop was interposed.

The embryological origin of proximal oesophageal atresia is not clearly understood and has been attributed to localized pressure by vascular anomalies or remnant on the developing oesophagus (Langman, 1952). Failure of the normal embryonal process of separation of the respiratory tract from the oesophagus may result in tracheooesophageal fistula, which is the commonest and best known anomaly in this group; oesophageal cysts lined by respiratory epithelium (Case 33182, 1947; Totten, Stout, Humphreys, and Moore, 1953); oesophageal stenosis due to tracheobronchial remnants with or without cartilage; lung bud of oesophageal origin (Gans and Potts, 1951; Davidson, 1956; St. Raymond, Hardy, and Robbins, 1956); and ectopic origin of the right main bronchus from the oesophagus (Keeley and Schairer, 1960; Thomson and Aquino, 1962; Hanna, 1964).

The embryological explanation of the presently discussed anomaly lies in the oesophageal $\vec{z}$ sequestration of a portion of the tracheobronchial anlage before separation. The distal location of the heterotopic tissue is explicable by the differential growth rates of the oesophagus and the tracheobronchial anlage with greater caudal growth of the former.

Apart from the cases reported by Spath and Ratzenhofer (1959), Bergmann and Charnas (1958), and Fonkalsrud (1972), all cases showed considerable histological similarity; cartilage was present in all and was probably of prime importance in producing oesophageal stenosis. The amount ranges from complete rings to aggregates visible microscopically. Crescents of peripherally situated cartilage were present in the majority.

Thirteen of the 14 cases possessed seromucous glands quite unlike the normal oesophageal glands and analogous to the normal seromucous tracheobronchial glands. Ducts lined by 'respiratory epithelium' and surrounded by lymphoid mantles were present in some cases but were not a constant feature. It may not be justified to term the columnar ciliated epithelium found in some cases respiratory or of bronchial origin, for it may represent a localized arrest in development and persistence of the embryonic oesophageal epithelium.

In the case reported by Goldman and Ban N (1972) the presence of tracheobronchial remnants in the proximal oesophageal pouch was associated with atresia distally. Histologically it showed intimate blending of the glandular and cartilaginous elements which was totally dissimilar from $\stackrel{D}{\rightarrow}$ the remaining cases which showed topographical organization similar to that of the bronchial tree.

Although the co-existence of distal oesophageal obstruction with oesophageal atresia and associated tracheo-oesophageal fistula has been reported 
previously, the distal obstruction in those cases was not due to ectopic tracheobronchial tissue (Gross, 1953; Overton and Creech, 1958). Our two cases showed a similar clinical presentation, and in both the provisional diagnosis was that of oesophageal stricture secondary to gastric reflux. In neither was reflux demonstrated on radiological examination or oesophagitis seen at oesophagoscopy. The presence of tracheobronchial remnant in the distal oesophageal segment after the surgical treatment of oesophageal atresia with associated tracheo-oesophageal fistula should be borne in mind in patients who develop symptoms of distal oesophageal obstruction.

I should like to thank Mr. H. C. Nohl-Oser, consultant cardiothoracic surgeon, under whose care the first patient was admitted, for all his helpful criticisms; Dr. S. Tucker, who referred the patient; and Mr. L. D. Abrams for his permission to publish the second case. I wish to acknowledge the help given by Dr. A. Bennett, consultant pathologist, Mount Vernon Hospital, Middlesex and Drs. I. D. Rushton and L. Jones, consultant pathologists, United Birmingham Hospitals, and to thank Mr. Tom Dee, of the Medical Illustration Department, United Birmingham Hospitals for his help with the photographs.

\section{REFERENCES}

Beatty, C. C. (1928). Congenital stenosis of the oesophagus. British Journal of Children's Disease, 25, 237.

Bergmann, M. and Charnas, R. M. (1958). Tracheobronchial rests in the esophagus, their relation to some benign strictures and certain types of cancer of the esophagus. Journal of Thoracic Surgery, 35, 97.

Case Records of the Massachusetts General Hospital (1947). Case 33182. Congenital tracheo-bronchial cyst of the esophageal wall. New England Journal of Medicine, 236, 672.

Castleman, B. (1956). Abortive congenital esophagotracheal fistula. Case 42411. Case Records of the Massachusetts General Hospital. New England Journal of Medicine, 255, 707.

Davidson, J. S. (1956). A case of congenital oesophageal diverticulum, lower accessory lobe, and oesophagobronchial fistula. British Journal of Surgery, 43, 417.

Fonkalsrud, E. W. (1972). Esophageal stenosis due to tracheobronchial remnants. American Journal of Surgery, 124, 101.
Frey, E. K. and Duschl, L. (1936). Der Kardiospasmus. Ergebenisse der Chirurgie und Orthopaedie, $29,637$.

Gans, S. L. and Potts, W. J. (1951). Anomalous lobe of lung arising from the esophagus. Journal of Thoracic Surgery, 21, 313.

Goldman, R. L. and Ban, J. L. (1972). Chondroepithelial choristoma of the esophagus associated with esophageal atresia. Journal of Thoracic and Cardiovascular Surgery, 63, 318.

Gross, R. E. (1953). The Surgery of Infancy and Childhood. W. B. Saunders, Philadelphia and London.

Hanna, E. A. (1964). Broncho-oesophageal fistula with total sequestration of the right lung. Annals of Surgery, 159, 599.

Ishida, M., Tsuchida, Y., Saito, S., and Tsunoda, A. (1969). Congenital esophageal stenosis due to tracheobronchial remnants. Journal of Paediatric Surgery, 4, 339.

Keeley, J. L. and Schairer, A. E. (1960). The anomalous origin of the right main bronchus from the esophagus. Annals of Surgery, 152, 871 .

Kumar, R. (1962). A case of congenital oesophageal stricture due to a cartilaginous ring. British Journal of Surgery, 49, 533.

Langman, J. (1952). Oesophageal atresia accompanied by a remarkable vessel anomaly. Archivum Chirurgicum Neerlandicum, 4, 39.

Overton, R. C. and Creech, O. (1958). Unusual esophageal atresia with distant membranous obstruction of the esophagus. Journal of Thoracic Surgery, 35, 674.

Paulino, F., Roselli, A., and Aprigliano, F. (1963). Congenital esophageal stricture due to tracheobronchial remnants. Surgery, 53, 547.

St. Raymond, A. H., Hardy, J. D., and Robbins, S. G. (1956). Lower accessory lung communicating with the esophagus and associated with congenital diaphragmatic hernia. Journal of Thoracic Surgery, 31, 354.

Spath, F. and Ratzenhofer, M. (1959). Ueber die angeborene Oesophagusstenose. Wiener klinische Wochenschrift, 71, 723.

Thomson, N. B. Jr. and Aquino, T. (1962). Anomalous origin of the right main-stem bronchus. Surgery, 51, 668.

Totten, R. S., Stout, A. P., Humphreys, G. H., and Moore, R. L. (1953). Benign tumors and cysts of the esophagus. Journal of Thoracic Surgery, 25, 606 .

Requests for reprints to: A. K. Deiraniya, F.R.C.S., Cardiothoracic Unit, Queen Elizabeth Hospital, Edgbaston, Birmingham B15 2TH. 